\title{
Plasma androgens after a single oral dose of testosterone undecanoate
}

\author{
GILLIAN GEERE, JENNIFER JONES, SHELIA M ATHERDEN, AND D B GRANT
}

The Institute of Child Health, London

SUMmARY Total plasma androgens (PA) were measured in 9 hypogonadal males aged between 13 and $21 \frac{1}{2}$ years after a single oral dose of testosterone undecanoate (TU). With the exception of one patient, all showed a rise in PA with peak values between 7.7 and $38.0 \mathrm{nmol} / 1$ at 2 to 7 hours. A further patient aged 15.7 years who was given an $80-\mathrm{mg}$ dose had a peak PA level of $71.2 \mathrm{nmol} / 1$. In all patients PA returned to basal levels at 24 hours. In 4 patients plasma testosterone and dihydrotestosterone were measured, both rose after oral TU, and relatively high plasma dihydrotestosterone values were obtained. While these results indicate that TU is effective in young people, the very high peak androgen levels found in several of them after $40 \mathrm{mg}$ TU suggest that this dose may be excessive in patients in whom growth is not complete.

Treatment with androgen is generally necessary in boys with hypogonadism to produce normal secondary sexual development at adolescence. While satisfactory results can be obtained with fairly low doses of testosterone esters given by injection every 4 to 6 weeks, an effective oral preparation would be more convenient. Testosterone undecanoate (TU) (Organon Laboratories), a lipid-soluble preparation which is absorbed into the intestinal lymphatics and which does not have the hepatotoxic effects of $17 \alpha$ methyl-testosterone, has been used with success in hypogonadal men.1-2 However, there is no information on the appropriate dose for younger people. The plasma androgen levels after a single dose of testosterone undecanoate in 10 young hypogonadal males are described.

\section{Subjects and methods}

Ten males aged between 13 and $21 \frac{1}{2}$ years were studied. Clinical details are given in Table 1 . In 9 of them previous surgical exploration for undescended testes had shown bilateral remnants of vas with either no recognisable testes (Cases 1-7) or

\footnotetext{
The Hospital for Sick Children, London

GILLIAN GEERE, biochemist

SHELIA M ATHERDEN, chief technician

D B GRANT, consultant paediatrician

The Institute of Child Health, London

JENNIFER JONES, technician
}

Table 1 Clinical details of the 10 patients given testosterone undecanoate. Basal values for serum $\mathrm{LH}$ and $\mathrm{FSH}$ are also given.

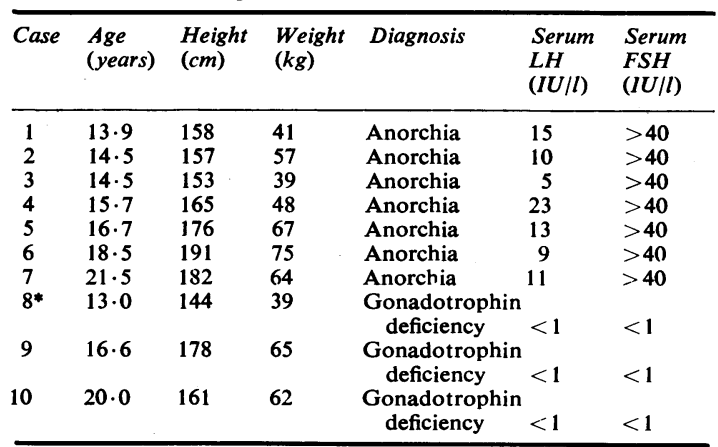

*No previous treatment with testosterone.

very small hypoplastic testes (Cases 9 and 10). Surgical exploration had not been carried out in one boy with undescended testes associated with gonadotrophin deficiency and hyposmia (Kallman's syndrome). Nine of them had already been treated with a depot preparation of testosterone oenanthate (100-250 mg every 4 to 8 weeks) for 1 to $3 \cdot 4$ years. These patients, none of whom had shown spontaneous pubertal development before treatment, were studied 4 to 6 weeks after their last injections.

After collection of a basal venous blood sample, a 
single dose of testosterone undecanoate was given orally between 0930 and 1030 hours after a normal breakfast. Further blood samples were taken 2, 4, 7, and 24 hours later. Nine patients were given $40 \mathrm{mg}$ TU and a dose of $80 \mathrm{mg}$ was given to one patient (Case 4).

Total plasma androgens (PA) were measured by radioimmunoassay in all the samples after extraction with ether:hexane $(4: 1)$. In 4 patients plasma testosterone (T) and dihydrotestosterone (DHT) were assayed separately after chromatography of the plasma extract on celite microcolumns and elution with $10 \%$ ethyl acetate in iso-octane (DHT fraction) and $20 \%$ ethyl acetate in iso-octane (T fraction). ${ }^{3-4}$ In general the PA values were lower than the combined values for $\mathrm{T}$ and DHT (PA $0.78(\mathrm{~T}+$ DHT) $+0 \cdot 8 ; \mathrm{r} 0 \cdot 99$ ). This can probably be explained by the lower affinity of the antiserum for DHT, resulting in an underestimate of the DHT contribution to the PA results.

Using these assays the mean ( $\pm 1 \mathrm{SD})$ plasma androgen levels in 8 healthy adult men were as follows: PA $16 \cdot 3 \pm 3 \cdot 1 \mathrm{nmol} / \mathrm{l} ; \mathrm{T} 13 \cdot 1 \pm 3 \cdot 3$ $\mathrm{nmol} / \mathrm{l}$; DHT $2.8 \pm 0.9 \mathrm{nmol} / \mathrm{l}$. The average DHT:T ratio was $0 \cdot 28$.

Luteinising hormone ( $\mathrm{LH})$ and follicle-stimulating hormone (FSH) were estimated in serum by double antibody radioimmunoassay using the MRC standards $68 / 40$ and $69 / 104$ respectively.

\section{Results}

Total androgens (Table 2). There was a rise in PA after administration of TU in all but one patient (Case 6). The timing of the peak value varied but in all patients the PA levels had returned to basal levels 24 hours later. There was considerable variation, from 7.7 to $38.0 \mathrm{nmol} / \mathrm{l}$, in the peak concentration after $40 \mathrm{mg}$ TU. The only patient to be given $80 \mathrm{mg}$ dose (Case 4) had a very high PA level, $71 \cdot 2 \mathrm{nmol} / 1$ at 2 hours, but this was not sustained.

Testosterone and dihydrotestosterone. In the 4 patients investigated (Cases 2, 4, 7, and 10), both $T$ and DHT levels increased after administration of TU (Table 3). The DHT:T ratios varied between 0.4 and $3 \cdot 1$, and were much higher than the ratios found in normal men. There was no evidence of any consistent change in the DHT:T ratio at different times after TU administration.

LH and FSH. The basal LH and FSH values are given in Table 1. Three patients had very low values, indicating the presence of hypogonadotrophic hypogonadism. The remainder had grossly raised
Table 2 Total plasma androgen levels (nmol/l) after testosterone undecanoate

\begin{tabular}{|c|c|c|c|c|c|}
\hline \multirow[t]{2}{*}{ Case } & \multicolumn{5}{|c|}{ Time (hours) } \\
\hline & 0 & 2 & 4 & 7 & 24 \\
\hline 1 & 0.2 & $7 \cdot 7$ & $1 \cdot 9$ & $0 \cdot 3$ & 0.4 \\
\hline 2 & 0.6 & $7 \cdot 0$ & $11 \cdot 0$ & $15 \cdot 5$ & $1 \cdot 5$ \\
\hline 3 & $1 \cdot 1$ & $13 \cdot 2$ & $8 \cdot 8$ & 3.9 & - \\
\hline $4^{*}$ & 0.9 & $72 \cdot 2$ & $24 \cdot 5$ & $6 \cdot 2$ & 0.5 \\
\hline 5 & $0 \cdot 5$ & $7 \cdot 5$ & $5 \cdot 3$ & $10 \cdot 5$ & $1 \cdot 5$ \\
\hline 6 & $1 \cdot 0$ & $1 \cdot 0$ & $1 \cdot 2$ & $1 \cdot 0$ & $1 \cdot 0$ \\
\hline 7 & $2 \cdot 7$ & $5 \cdot 5$ & $9 \cdot 7$ & $7 \cdot 0$ & $2 \cdot 5$ \\
\hline 8 & 0.4 & $29 \cdot 9$ & $1 \cdot 2$ & $1 \cdot 6$ & 0.2 \\
\hline 9 & $1 \cdot 2$ & $9 \cdot 8$ & $10 \cdot 2$ & $1 \cdot 8$ & $1 \cdot 1$ \\
\hline 10 & $1 \cdot 1$ & $38 \cdot 0$ & $19 \cdot 0$ & $12 \cdot 0$ & $1 \cdot 1$ \\
\hline
\end{tabular}

*80 $\mathrm{mg}$ testosterone undecanoate given.

Conversion: SI to traditional units-PA: $1 \mathrm{nmol} / 1 \approx 0.288 \mathrm{ng} / \mathrm{ml}$.

Table 3 Plasma testosterone $(T)$ (nmol/l) and dihydrotestosterone $(\mathrm{DHT})(\mathrm{nmol} / \mathrm{l})$ in 4 patients after testosterone undecanoate

\begin{tabular}{|c|c|c|c|}
\hline \multirow[t]{2}{*}{ Case } & \multicolumn{3}{|c|}{ Time (hours) } \\
\hline & 2 & 4 & 7 \\
\hline \multicolumn{4}{|l|}{2} \\
\hline Testosterone $(\mathrm{nmol} / \mathrm{l})$ & $1 \cdot 0$ & $7 \cdot 7$ & $9 \cdot 8$ \\
\hline Dihydrotestosterone $(\mathrm{nmol} / \mathrm{l})$ & $3 \cdot 1$ & $8 \cdot 6$ & $8 \cdot 9$ \\
\hline \multicolumn{4}{|l|}{$4^{*}$} \\
\hline $\begin{array}{l}\text { Testosterone (nmol/1) } \\
\text { Dihydrotestosterone (nmol/l) }\end{array}$ & $62 \cdot 0$ & $19 \cdot 2$ & $2 \cdot 5$ \\
\hline${ }_{7}$ Dihydrotestosterone (nmol/l) & $28 \cdot 0$ & $7 \cdot 8$ & $5 \cdot 2$ \\
\hline Testosterone (nmol/1) & $3 \cdot 3$ & $5 \cdot 5$ & 5.4 \\
\hline Dihydrotestosterone (nmol/1) & $5 \cdot 2$ & $3 \cdot 9$ & $5 \cdot 6$ \\
\hline \multicolumn{4}{|l|}{10} \\
\hline Testosterone $(\mathrm{nmol} / \mathrm{l})$ & 29.8 & $9 \cdot 2$ & $5 \cdot 8$ \\
\hline Dihydrotestosterone (nmol/l) & $15 \cdot 4$ & $10 \cdot 6$ & $5 \cdot 1$ \\
\hline
\end{tabular}

FSH values, indicating primary hypogonadism. Basal LH levels were moderately increased and there were no consistent changes after TU.

\section{Discussion}

It is already well established that testosterone undecanoate given by mouth is effective in raising plasma androgen levels in adult men. For example, Nieschlag et al..$^{5}$ found that plasma androgen levels rose in normal men 4 to 5 hours after $100 \mathrm{mg}$ testosterone undecanoate had been given by mouth in arachis oil, and Franchimont et al..$^{2}$ found that plasma testosterone, dihydrotestosterone, and androstenedione rose in a group of hypogonadal men, while plasma LH and FSH fell. The present study was carried out to evaluate the plasma androgen levels occurring in younger males after administration of testosterone undecanoate. The results show that this preparation is effective in young men with hypogonadism. All but one had rises in plasma androgens, but in several the peak 
plasma levels were much higher than would be expected in normal men. There was also considerable variation in the timing of the peak androgen level but in all but one a rise was apparent 2 hours later, and by 24 hours the plasma levels had returned to basal values.

In the 4 patients in whom both $\mathrm{T}$ and DHT were measured, the peak plasma DHT values were very much higher than would be expected in normal men, and similar results were reported by Hirschhäuser et al. ${ }^{1}$

We expected that plasma LH would be suppressed after testosterone undecanoate administration, but no consistent changes were found after a 40-mg dose. This may be due to the relatively brief increase in plasma $\mathrm{T}$ in our study, as Franchimont et al..$^{2}$ found progressive suppression of plasma $\mathrm{LH}$ during continued administration of testosterone undecanoate to hypogonadal men.

While these results do not permit any conclusions on the place of testosterone undecanoate in the longterm management of adolescent boys with hypogonadism, they suggest that a $40-\mathrm{mg}$ dose may be excessive, particularly in the early stages of treatment. Very high plasma androgen levels were obtained with this dose and it is possible that these could lead to disproportionately rapid bone maturation. The short-lived effect of a single dose may not be a disadvantage as $\mathrm{T}$ secretion is episodic in adolescent boys $^{6}$ and the metabolic effect may persist as a result of tissue binding. The high plasma DHT levels also call for caution when treating young patients with this preparation. There is some evidence that the metabolic effects of T and DHT differ in different tissues, for example muscle, ${ }^{7}$ and the relative importance of DHT in adolescent growth and bone maturation is still not clear.
We thank Mr D R Thomas, Organon Laboratories Ltd for the supply of testosterone undecanoate.

$\mathbf{J} \mathbf{J}$ is supported by a grant from the MRC and G $G$ by grants from Organon Laboratories, the Smith, Kline, and French Foundation, and the Joint Research Board of The Hospital for Sick Children and Institute of Child Health.

\section{References}

1 Hirschhäuser C, Hopkinson C R N, Sturm G, Coert A. Testosterone undecanoate: a new orally active androgen. Acta Endocrinol (Kbh) 1975; 80: 179-87.

2 Franchimont P, Kićović P M, Mattei A, Roulier R. Effects of oral testosterone undecanoate in hypogonadal male patients. Acta Endocrinol [Suppl] (Kbh) 1977; 85: Supplement 212, 118.

3 Abraham G E, Buster J E, Lucas L A, Corrales P C, Teller R C. Chromatographic separation of steroid hormones for use in radioimmunoassay. Anal Lett 1972; 5: 509-17.

4 Coyotupa J, Parlow A F, Abraham G E. Simultaneous radioimmunoassay of plasma testosterone and dihydrotestosterone. Anal Lett 1972; 5: 329-40.

5 Nieschlag E, Mauss J, Coert A, Kićović P. Plasma androgen levels in men after oral administration of testosterone undecanoate. Acta Endocrinol 1975; 79: 366-74.

- Boyar R M, Rosenfeld R S, Kapen S, et al. Human puberty: simultaneous augmented secretion of luteinizing hormone and testosterone during sleep. $J$ Clin Invest 1974; 54: 609-18.

7 Mainwaring W I P, Mangan F R. A study of androgen receptors in a variety of androgen sensitive tissues. $J$ Endocrinol 1973; 59: 121-39.

Correspondence to Dr D B Grant, The Hospital for Sick Children, Great Ormond Street, London WC1N $3 \mathrm{JH}$.

Received 3 April 1979 